\title{
The role of acidification in the inhibition of Neisseria gonorrhoeae by vaginal lactobacilli during anaerobic growth
}

\author{
Michelle A Graver ${ }^{\dagger}$, Jeremy J Wade ${ }^{*}$
}

\begin{abstract}
Background: Vaginal lactobacilli protect the female genital tract by producing lactic acid, bacteriocins, hydrogen peroxide or a local immune response. In bacterial vaginosis, normal lactobacilli are replaced by an anaerobic flora and this may increase susceptibility to Neisseria gonorrhoeae, a facultative anaerobe. Bacterial interference between vaginal lactobacilli and $\mathrm{N}$. gonorrhoeae has not been studied in liquid medium under anaerobic conditions. By cocultivating $N$. gonorrhoeae in the presence of lactobacilli we sought to identify the relative contributions of acidification and hydrogen peroxide production to any growth inhibition of $N$. gonorrhoeae.
\end{abstract}

Methods: Three strains of $\mathrm{N}$. gonorrhoeae distinguishable by auxotyping were grown in the presence of high concentrations $\left(10^{7}-10^{8} \mathrm{cfu} / \mathrm{mL}\right)$ of three vaginal lactobacilli (L. crispatus, L. gasseri and L. jensenii) in an anerobic liquid medium with and without 2-(N-morpholino)-ethanesulfonic (MES) buffer. Fusobacterium nucleatum was used as an indicator of anaerobiosis. Bacterial counts were performed at 15, 20 and $25 \mathrm{~h}$; at $25 \mathrm{~h} \mathrm{pH}$ and hydrogen peroxide concentrations were measured.

Results: Growth of F. nucleatum to $>10^{8} \mathrm{cfu} / \mathrm{mL}$ at $25 \mathrm{~h}$ confirmed anaerobiosis. All bacteria grew in the anaerobic liquid medium and the addition of MES buffer had negligible effect on growth. L. crispatus and L. gasseri produced significant acidification and a corresponding reduction in growth of $\mathrm{N}$. gonorrhoeae. This inhibition was abrogated by the addition of MES. L. jensenii produced less acidification and did not inhibit N. gonorrhoeae. Hydrogen peroxide was not detected in any experiment.

Conclusions: During anaerobic growth, inhibition of $N$. gonorrhoeae by the vaginal lactobacilli tested was primarily due to acidification and abrogated by the presence of a buffer. There was no evidence of a specific mechanism of inhibition other than acid production under these conditions and, in particular, hydrogen peroxide was not produced. The acidification potential of vaginal lactobacilli under anaerobic conditions may be their most important characteristic conferring protection against $N$. gonorrhoeae infection.

\section{Background}

The majority of healthy women harbor lactobacilli (LB) in the vagina at counts of $10^{7}-10^{9} \mathrm{cfu} / \mathrm{gm}$ secretions $[1,2]$. These protect the female genital tract by metabolising glycogen in shed epithelial cells to produce lactic acid, thereby generating a low $\mathrm{pH}$ environment. Most vaginal lactic acid is of the D-lactate isomer and therefore of bacterial, not human, origin. LB may also inhibit opportunist bacteria through production of bacteriocins,

\footnotetext{
* Correspondence: jimwade@nhs.net

† Contributed equally

Medical Microbiology, King's College Hospital, Denmark Hill, London, SE5
} 9RS, UK hydrogen peroxide $\left(\mathrm{H}_{2} \mathrm{O}_{2}\right)$ or local immune stimulation, as well as through nutrient and stearic competition.

The hallmark of bacterial vaginosis (BV) - a highly prevalent condition of global public health importance is replacement of normal vaginal LB by a mixed flora of anaerobic bacteria. Studies suggest that an abnormal vaginal flora increases susceptibility to infection with sexually-transmitted pathogens including Neisseria gonorrhoeae (NG).

Evidence accrues that NG grows anaerobically in vivo: NG may be recovered with obligate anaerobes from clinical material and NG proteins induced anaerobically include a nitrite reductase, antibodies to which are

\section{Biomed Central}


present in sera of infected patients $[3,4]$. Bacterial interference between LB and NG growing anaerobically in liquid medium has not been studied. By co-cultivating NG and LB we sought to identify the relative contributions of $\mathrm{LB}$ acidification and $\mathrm{H}_{2} \mathrm{O}_{2}$ production to any inhibition of NG under anaerobic conditions.

\section{Methods \\ Media}

A defined medium [5] rendered anaerobic with 'Oxyrase for Broth' (Oxyrase Inc, Ohio, USA) at $20 \mathrm{~mL} / \mathrm{L}$ [6] was used, with and without $30 \mathrm{mM}$ 2-(N-morpholino)-ethanesulfonic acid (MES) buffer adjusted to an initial $\mathrm{pH}$ 6.5 with $1 \mathrm{M} \mathrm{HCl}$. The medium was sterilized through a $0.22 \mu$ filter (Nalgene) and $7 \mathrm{~mL}$ volumes added to $7 \mathrm{~mL}$ screw-top plastic bijoux (Sterilin) giving a headspace above the liquid in each bijoux of approximately $1 \mathrm{~mL}$. Media were pre-reduced before inoculation by incubating at $37^{\circ} \mathrm{C}$ for $\geq 2 \mathrm{~h}$. Bijoux containing medium with rezasurin sodium at $0.002 \mathrm{~g} / \mathrm{L}$ were included as uninoculated reduction controls in each experiment.

\section{Bacterial strains}

The strains studied included three LB: Lactobacillus crispatus NCTC 4505 (LC), Lactobacillus gasseri ATCC 9857 (LG) and Lactobacillus jensenii ATCC 25258 (LJ). Modified tetramethylbenzidine (TMB) medium, prepared and used as described by Rabe and Hillier [7], revealed that the LJ, LC and LG were strong, weak and negative $\mathrm{H}_{2} \mathrm{O}_{2}$ producers, respectively. Three clinical isolates of NG distinguishable by auxotyping by the method of Copley \& Egglestone [8] were studied. In each experiment Fusobacterium nucleatum ATCC 25586 (FN) was included as an indicator of anaerobiosis.

\section{Preparation of inocula}

Inocula were prepared from overnight growth on chocolate agar in $5 \% \mathrm{CO}_{2}$ at $37^{\circ} \mathrm{C}$ for $\mathrm{NG}$, from blood agar incubated anaerobically overnight at $37^{\circ} \mathrm{C}$ for $\mathrm{FN}$, and from blood agar incubated in $5 \% \mathrm{CO}_{2}$ at $37^{\circ} \mathrm{C}$ for $48 \mathrm{~h}$ for LB (media from Oxoid, Basingstoke, UK).

\section{Monomicrobial culture}

Monomicrobial growth studies were done to ensure that all bacteria were capable of growth in the medium, to identify any effect of MES buffer on growth, and to confirm anaerobiosis by growth of the anaerobe FN. Bacteria were suspended in phosphate-buffered saline (PBS) and suspension added to media to give an inoculum of $10^{4}-10^{5}$ $\mathrm{cfu} / \mathrm{mL}$ for monomicrobial growth studies for all bacteria.

\section{Co-cultivation}

Co-cultivation experiments were designed to demonstrate whether high concentrations of LB affect the growth of $\mathrm{NG}$ and if the addition of a $\mathrm{pH}$ buffer had any influence. In co-cultivation experiments, the growth of each NG in the presence of each LB was assessed by adding an inoculum of $10^{4}-10^{5} \mathrm{cfu} / \mathrm{mL}$ of each NG (prepared as above) to a high inoculum of each LB. This high inoculum, of $10^{6}-10^{7} \mathrm{cfu} / \mathrm{mL}$, was achieved by preparing a suspension of LB in PBS before adding to the media; monomicrobial growth curves were also done for the LB using this higher inoculum.

\section{Sampling, colony counts and growth curves}

Capped bijoux were incubated at $37^{\circ} \mathrm{C}$, and at times $15 \mathrm{~h}, 20 \mathrm{~h}$ and $25 \mathrm{~h}$ resazurin indicator controls were examined and confirmed reduction at inoculation and up to at least $25 \mathrm{~h}$. At the same time intervals, counts were done after vortexing for $5 \mathrm{~s}$, on serial $10^{-2}$ dilutions in PBS on chocolate agar for NG and blood agar for LB and FN using a spiral plater (Don Whitley, UK). At $25 \mathrm{~h}$ $\mathrm{pH}$ was measured using a Mettler Toledo 'SevenEasy' $\mathrm{pH}$ meter, and $\mathrm{H}_{2} \mathrm{O}_{2}$ assayed by pipetting $50 \mu \mathrm{L}$ of medium on to Quantofix Peroxide 100 test strips and recording the colour change as per the manufacturer's instructions (Macherey-Nagel GmbH \& Co KG, Germany). These strips are capable of detecting 1-100 mg/L peroxide. All plates were incubated at $37^{\circ} \mathrm{C}$ for $48-72 \mathrm{~h}$ : the chocolate agar for NG and blood agar for LB plates in $5 \% \mathrm{CO}_{2}$, and blood agar for $\mathrm{FN}$ in anaerobic jars. Colonies were counted using an aCOLyte colony counter (Don Whitley, UK). All experiments were in triplicate. To demonstrate growth in the media, and any effect of MES buffer, growth curves were prepared for the FN, the three NG, and the three LB (for the latter, from both low and high inocula), with and without MES, using the median bacterial count at each time point. Similarly, in co-cultivation experiments growth curves for the three NG in the presence of each of the LB, with and without MES buffer, were prepared by plotting median values.

\section{Results}

The median counts (median $\log _{10} \mathrm{cfu} / \mathrm{mL}$ ) of triplicates for the obligate anaerobe FN at times 0 and $25 \mathrm{~h}$ were 5.27 and 8.2, respectively, confirming anaerobiosis (Figure 1A). All LB and NG grew in media with and without MES buffer in the monomicrobial growth studies (Figure $1 \mathrm{~B}$ and $1 \mathrm{C}$ ). LB at the high inoculum used in co-cultivation experiments grew over the first $15 \mathrm{~h}$ after inoculation and remained viable thereafter (Figure 1D). Throughout, the addition of MES had negligible effect on growth.

In co-cultivation experiments, the median $\log _{10} \mathrm{cfu} / \mathrm{mL}$ inocula for LB and NG were 6.78 and 4.0, respectively (Figure 1D \& Figure 2). In the absence of MES buffer, both $\mathrm{LC}$ and $\mathrm{LG}$ reduced the $\mathrm{pH}$ by $>1 \mathrm{pH}$ point by 


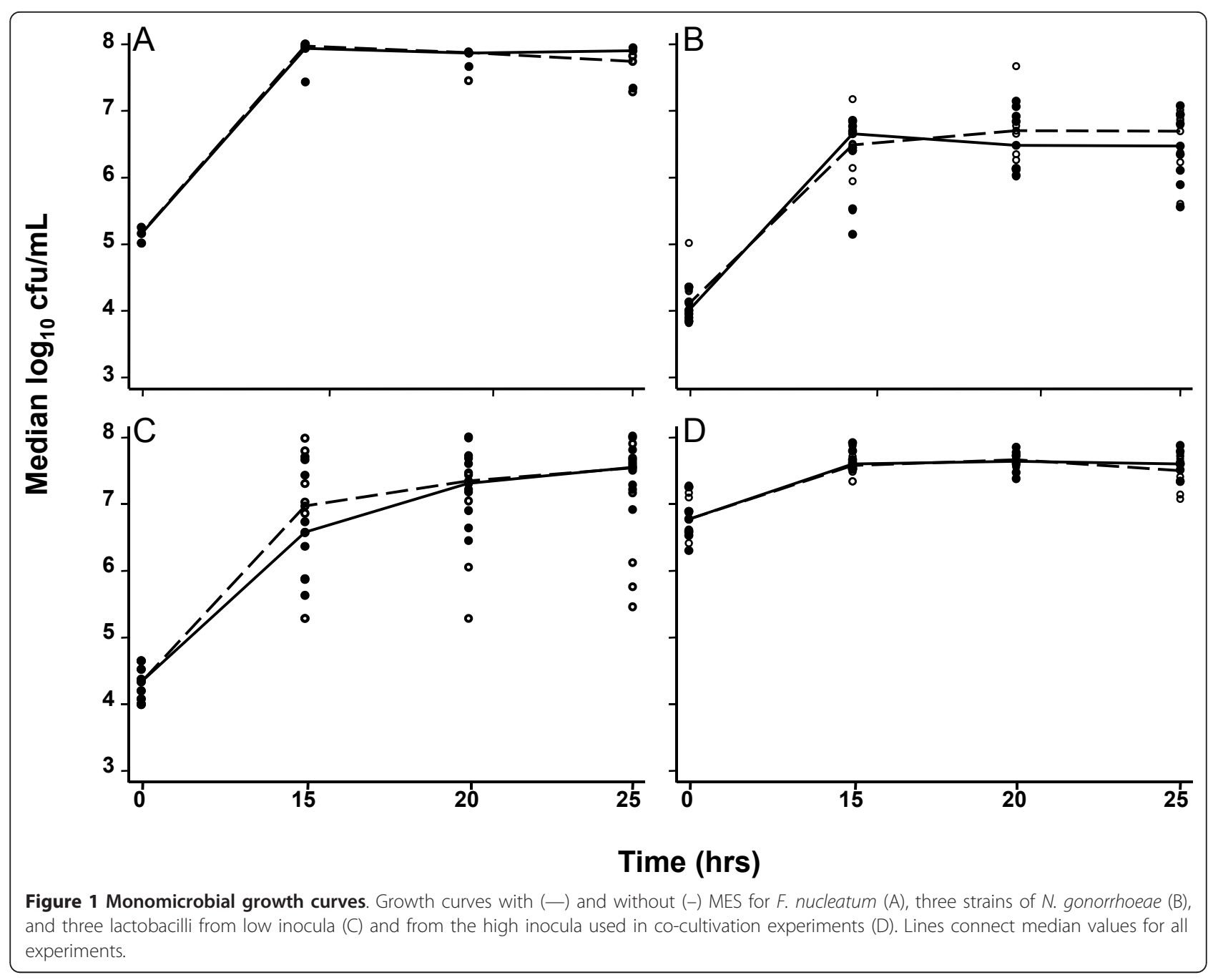

$25 \mathrm{~h}$; MES resisted this acidification, with a $\mathrm{pH}$ fall of $<0.5 \mathrm{pH}$ value for both. In contrast, LJ reduced the $\mathrm{pH}$ by only $0.7 \mathrm{pH}$ point with a correspondingly lower $\mathrm{pH}$ fall in the presence of MES. Although the three NG grew in the presence of a high concentration of each LB, NG growth with LC and LG was reduced compared to growth without LB, and MES abrogated this inhibition. The presence of LJ had no effect on NG whether MES was included or not. $\mathrm{H}_{2} \mathrm{O}_{2}$ was not detected at $25 \mathrm{~h}$ in any experiment.

\section{Discussion}

The LB studied here include representatives of the three species most frequently recovered from the healthy premenopausal vagina: $L$. crispatus, $L$. gasseri and L. jensenii. The normal vaginal flora plays a key role in maintaining vaginal health and, compared to the flora at other mucosal surfaces, is relatively simple in health: most women are colonized by a predominant species of LB. BV is a common condition - with an incidence of approximately
$20-30 \%$ of adult women - characterized by loss of the protective LB flora in the vagina. BV is an important public health problem as it is a risk factor for obstetric complications and the sexually-transmitted infections gonorrhoea, Chlamydia trachomatis and Trichomonas vaginalis [9-13]. The normal vagina is anaerobic with pressures of $\mathrm{O}_{2}$ and $\mathrm{CO}_{2}$ lower and higher, respectively, than atmospheric levels, though menstruation increases oxygen tension [14]. In BV, LB are replaced by a mixture of anaerobic bacteria and antimicrobials with activity against anaerobes, such as metronidazole and clindamycin, are the mainstay of treatment.

Hydrogen peroxide production is considered an important protective characteristic of LB comprising the normal vaginal flora. TMB medium, originally described by Eschenbach et al [15] and optimized by Rabe \& Hillier [7], demonstrates the ability of a LB to produce $\mathrm{H}_{2} \mathrm{O}_{2}$ when colonies grown anaerobically on the medium are subsequently exposed to air. Although there is an association between $\mathrm{H}_{2} \mathrm{O}_{2}$ production and a stable, 


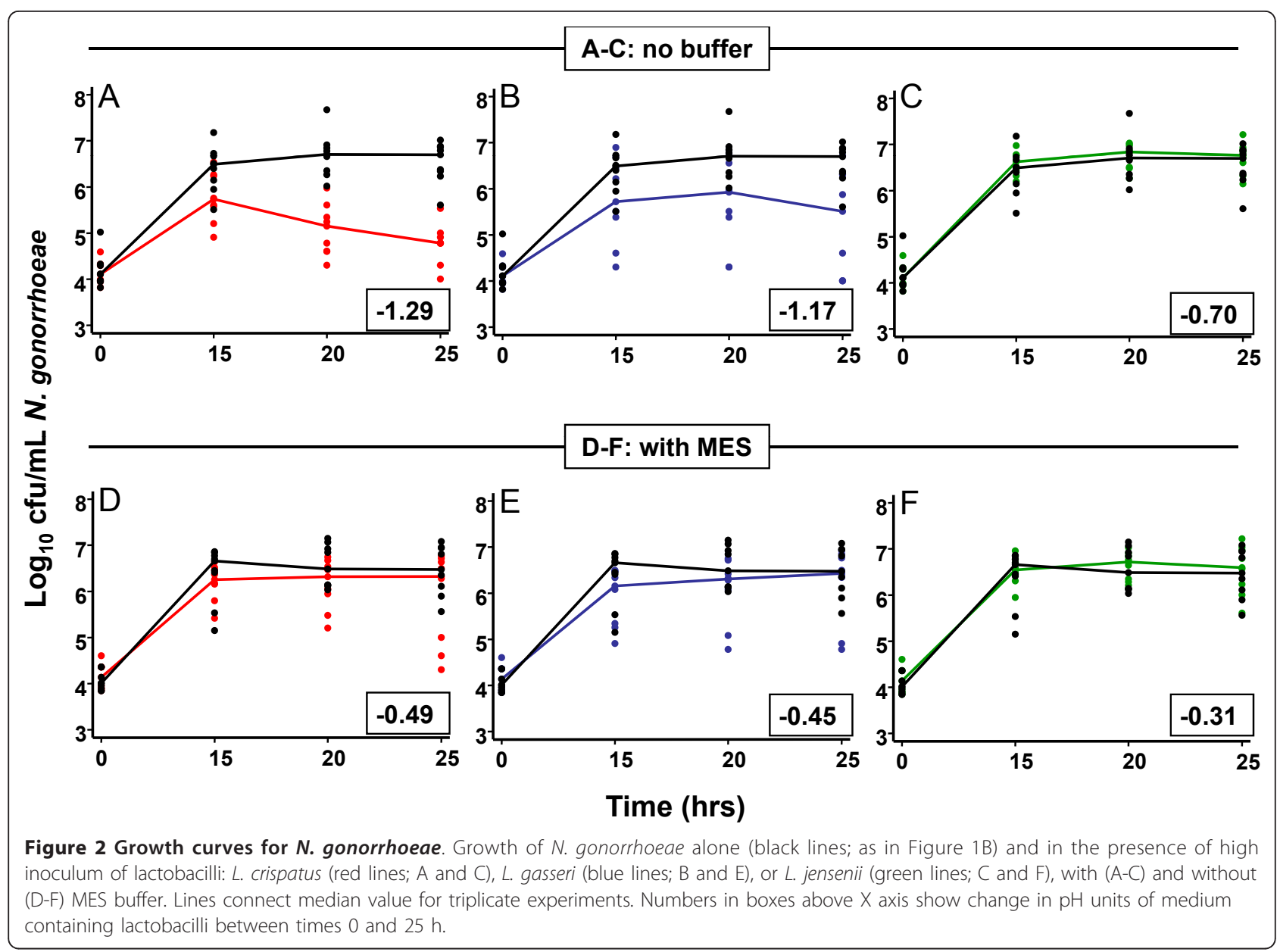

and therefore protective, vaginal LB flora, it is unclear whether LB produce $\mathrm{H}_{2} \mathrm{O}_{2}$ under the low oxygen tensions found in either the normal or BV vagina $[16,17]$. The need for agitation of cultures to generate detectable $\mathrm{H}_{2} \mathrm{O}_{2}$ has been described before [16]. It is feasible that LB capable of producing $\mathrm{H}_{2} \mathrm{O}_{2}$ do so for self-preservation when oxygen levels increase during menses. The antibacterial effects of $\mathrm{H}_{2} \mathrm{O}_{2}$, either directly or in concert with halide ions and myeloperoxidases [18], may permit LB to suppress other bacteria and thereby control the vaginal flora. This would reconcile the findings of studies that emphasize the importance of $\mathrm{H}_{2} \mathrm{O}_{2}$ producing $\mathrm{LB}$ for vaginal health with the anaerobic conditions found in the vagina.

We are not aware of another study of bacterial interference between LB and NG during anaerobic co-cultivation. Interactions between LB and NG have been sought using agar overlay methods $[17,19-21]$ or by brief coincubation [22] under aerobic conditions. Our results confirm that NG can grow under strictly anaerobic conditions and may be inhibited by vaginal LB growing under conditions more akin to those seen in the healthy or BV vagina than those previously used in for bacterial interference studies. This inhibitory action appears to be primarily due to acidification rather than $\mathrm{H}_{2} \mathrm{O}_{2}$ production as demonstrated by the correlation between the degree of inhibition and the acidification capabilities of individual $L B$, the effects of buffer, and lack of $\mathrm{H}_{2} \mathrm{O}_{2}$ production. It remains possible, however, that a bacteriocin produced at, or activated by, a lower $\mathrm{pH}$ could account for some of our findings. These observations suggest that those seeking to select LB for probiotic use in BV should address the acidification potential of candidate LB.

\section{Conclusions}

The normal vagina is anaerobic with pressures of $\mathrm{O}_{2}$ and $\mathrm{CO}_{2}$ lower and higher, respectively, than atmospheric levels. During anaerobic growth, inhibition of $N$. gonorrhoeae by the vaginal LB tested was primarily due to acidification, as evidenced by reduced inhibition is the presence of buffer. Under these conditions $\mathrm{H}_{2} \mathrm{O}_{2}$ was not produced by LB shown to be capable of $\mathrm{H}_{2} \mathrm{O}_{2}$ production using standard methods. The acidification 
potential of vaginal lactobacilli under anaerobic conditions may be an important characteristic conferring protection against NG infection.

\section{Abbreviations used}

BV: bacterial vaginosis; Cfu: colony-forming unit; FN: Fusobacterium nucleatum; $\mathrm{H}_{2} \mathrm{O}_{2}$ : hydrogen peroxide; L: litre; LB: lactobacilli; LC: Lactobacillus crispatus; LG: Lactobacillus gasseri; L: Lactobacillus jensenii; mL: millilitre; NG: Neisseria gonorrhoeae; PBS: phosphate-buffered saline.

\section{Authors' contributions}

Both authors contributed equally to the design and execution of experiments and preparation of the manuscript. Both authors have read and approved the final manuscript.

\section{Competing interests}

The authors declare that they have no competing interests.

Received: 2 November 2010 Accepted: 17 February 2011

Published: 17 February 2011

\section{References}

1. Eschenbach DA, Davick PR, Williams BL, Klebanoff SJ, Young-Smith K, Critchlow CM, Holmes KK: Prevalence of hydrogen peroxide-producing Lactobacillus species in normal women and women with bacterial vaginosis. J Clin Microbiol 1989, 27:251-256.

2. De Louvois J, Stanley VC, Leask BGS, Hurley R: Ecological studies of the microbial flora of the female lower genital tract. Proc Roy Soc Med 1975, 68:269-270.

3. Knapp JS, Clark VL: Anaerobic growth of Neisseria gonorrhoeae coupled to nitrite reduction. Infect Immun 1984, 46:176-181.

4. Clark VL, Campbell LA, Palermo DA, Evans TM, Klimpel KW: Induction and repression of outer membrane proteins by anaerobic growth of Neisseria gonorrhoeae. Infect Immun 1987, 55:1359-1364.

5. Wade JJ, Graver MA: A fully defined, clear and protein-free liquid medium permitting dense growth of Neisseria gonorrhoeae from very low inocula. FEMS Microbiol Lett 2007, 273:35-37.

6. Wade JJ, Graver MA: A liquid medium permitting anaerobic growth of Neisseria gonorrhoeae. J Microbiol Methods 2009, 79:364-366.

7. Rabe LK, Hillier SL: Optimization of media for detection of hydrogen peroxide production by Lactobacillus species. J Clin Microbiol 2003, 41:3260-3264.

8. Copley CG, Egglestone SI: Auxotyping of Neisseria gonorrhoeae isolated in the United Kingdom. J Med Microbiol 1983, 16:295-302.

9. Fethers KA, Fairley CK, Hocking JS, Gurrin LC, Bradshaw CS: Sexual risk factors and bacterial vaginosis: a systematic review and meta-analysis. CID 2008, 47:1426-1435.

10. Spear GT, St John E, Zariffard MR: Bacterial vaginosis and human immunodeficiency virus infection. AIDS Res Ther 2007, 4:25.

11. Shin LY, Kaul R: Say it with flora: maintaining vaginal health as a possible avenue for prevention of human immunodeficiency virus acquisition. J Infect Dis 2008, 197:1355-1357.

12. Morris M, Nicoll A, Simms I, Wilson J, Catchpole M: Bacterial vaginosis: a public health review. Br J Obstet Gynaecol 2001, 108:439-450.

13. Hillier SL, Krohn MA, Nugent RP, Gibbs RS: Characteristics of three vaginal flora patterns assessed by Gram stain among pregnant women. Am $J$ Obstet Gynecol 1992, 166:938-944

14. Hill DR, Brunner ME, Schmitz DC, Davis CC, Flood JA, Schlievert PM, WangWeigand SZ, Osborn TW: In vivo assessment of human vaginal oxygen and carbon dioxide levels during and post menses. J Appl Physiol 2005, 99:1582-1591.

15. Eschenbach DA, Davick PR, Williams BL, Klebanoff SJ, Young-Smith K, Critchlow CM, Holmes KK: Prevalence of hydrogen peroxide-producing Lactobacillus species in normal women and women with bacterial vaginosis. J Clin Microbiol 1989, 27:251-256.

16. Fontaine EA, Claydon E, Taylor-Robinson D: Lactobacilli from women with and without bacterial vaginosis and observations on the significance of hydrogen peroxide. Microb Ecol Hith Dis 1996, 9:135-141.
17. St Amant DC, Valentin-Bon IE, Jerse AE: Inhibition of Neisseria gonorrhoeae by Lactobacillus species that are commonly isolated from the female genital tract. Infect Immun 2002, 70:7169-7171.

18. Condon S: Responses of lactic acid bacteria to oxygen. FEMS Microbiol Rev 1987, 46:269-280.

19. Kaye D, Levison ME: In vitro inhibition of growth of Neisseria gonorrhoeae by genital microorganisms. Sex Transm Dis 1977, 4:1-3.

20. Saigh JH, Sanders CC, Sanders WE: Inhibition of Neisseria gonorrhoeae by aerobic and facultative anaerobic components of the endocervical flora: evidence for a protective effect against infection. Infect Immun 1978, 19:704-710.

21. Morin A, Saheb SA, Bisaillon JG, Beaudet R, Sylvestre M: Effect of culture medium on inhibition of growth of Neisseria gonorrhoeae by lactobacilli. Curr Microbiol 1980, 4:283-286.

22. Zheng $\mathrm{H}$, Alcorn TM, Cohen MS: Effects of $\mathrm{H}_{2} \mathrm{O}_{2}$-producing lactobacilli on Neisseria gonorrhoeae growth and catalase activity. J Infect Dis 1994, 170:1209-1215

doi:10.1186/1476-0711-10-8

Cite this article as: Graver and Wade: The role of acidification in the inhibition of Neisseria gonorrhoeae by vaginal lactobacilli during anaerobic growth. Annals of Clinical Microbiology and Antimicrobials 2011 $10: 8$

\section{Submit your next manuscript to BioMed Central and take full advantage of:}

- Convenient online submission

- Thorough peer review

- No space constraints or color figure charges

- Immediate publication on acceptance

- Inclusion in PubMed, CAS, Scopus and Google Scholar

- Research which is freely available for redistribution
C Biomed Central 